\title{
Aging effect of the precursor solution on the structural, morphological and opto- electrical properties of spray deposited CdO thin films
}

\author{
N. RAJA ${ }^{1,2}$, V.S. NAGARETHINAM ${ }^{2}$, A.R. BALU ${ }^{2, *}$ \\ ${ }^{1}$ Department of Physics, Anjalaiammal Mahalingam Engineering College, Kovilvenni, Tamilnadu, India. \\ ${ }^{2}$ PG and Research Department of Physics, AVVM Sri Pushpam College, Poondi - 613 503, Tamilnadu, India.
}

\begin{abstract}
Nanostructured $\mathrm{CdO}$ thin films have been prepared on glass substrates by spray pyrolysis technique using perfume atomizer from fresh and aged (1, 2, 3 and 4 days) precursor solutions. XRD studies confirm that all the films exhibit cubic crystal structure with a $\left(\begin{array}{lll}1 & 1 & 1\end{array}\right)$ preferential orientation. The preferential orientation factor $\mathrm{f}\left(\begin{array}{lll}1 & 1 & 1\end{array}\right)$ increases with an increase in aging the period of precursor solution. The $2 \theta$ value of the (llll 11 ) plane shifts towards lower Bragg angles with aging inferring an expansion in the lattice volume of the aged films. Increased crystallite size is observed for the 3-days aged film for which minimum strain and dislocation density values are obtained. Optical transparency increases with an increase in aging period of the precursor solution and the optical band gap exhibits a red shift from $2.48 \mathrm{eV}$ to $2.32 \mathrm{eV}$. Minimum resistivity of $0.78 \times 10^{-2} \Omega \cdot \mathrm{cm}$ is observed for the $\mathrm{CdO}$ film prepared from 3-days aged solution. The obtained results infer that the CdO film prepared from 3-days aged solution exhibits better physical properties than the others.
\end{abstract}

Keywords: X-ray diffraction; aging; crystal structure; preferential orientation; precursor

\section{Introduction}

Cadmium oxide (CdO), a n-type II-VI compound semiconductor due to its degenerate semiconducting and electronic properties finds numerous applications in optical communications, photodiodes, phototransistors, gas sensors and lowemissive windows [1]. CdO crystallizes in a cubic crystal structure belonging to Fm3m space group, with nearly metallic conductivity and direct band of $2.3 \mathrm{eV}$ with two indirect transitions at lower energies [2]. Native defects such as oxygen vacancies and cadmium interstitials strongly influence the conductivity of pure $\mathrm{CdO}$ [3]. The high electrical conductivity and optical transparency possessed by $\mathrm{CdO}$ make it suitable for photovoltaic and optoelectronic applications. However the low band gap of $\mathrm{CdO}$ restricts its applications in the visible region of solar spectrum. Nowadays, in the majority of electronic devices and modern semiconductor technology, metal/semiconductor

*E-mail: arbalu757@gmail.com structures are used. Literature survey made on $\mathrm{CdO}$ thin film based heterojunction diodes along with ptype silicon showed very good spectral response at both the infrared and blue regions of the visible wavelength [4]. To further improve the optoelectrical properties of pure $\mathrm{CdO}$ based heterojunctions, it is essential to perform a systematic investigation on its physical properties which can be influenced by the growth conditions of the deposition technique adopted to coat the film. Thin films of pure $\mathrm{CdO}$ have been grown by different physical and chemical techniques such as sputtering [5] pulsed laser deposition [6], spray pyrolysis [7], solgel [8], SILAR [9], etc. Among the chemical methods, spray pyrolysis is a simple, inexpensive technique capable of preparing high quality $\mathrm{CdO}$ thin films over a large area. It has been reported earlier that the following growth conditions such as substrate temperature [10] precursor molar concentration [11], solvent volume [3] and spray rate strongly influence the physical properties of spray deposited $\mathrm{CdO}$ thin films. Besides these spray parameters, it has been reported that the aging time 
of the precursor (spraying) solution also affects the physical properties of spray deposited thin films. The effect of aging time on the properties of solgel derived $\mathrm{ZnO}$ thin films has been reported by $\mathrm{Li}$ et al. [12]. In our previous work, we reported the precursor aging effect on the properties of spray deposited CdZnS thin films [13]. Reports on the effect of precursor aging time on the physical properties of undoped $\mathrm{CdO}$ thin films are very scarce in the literature. Hence, in this work, we report the effect of precursor aging time on the properties of $\mathrm{CdO}$ thin films fabricated by spray technique using perfume atomizer. The use of perfume atomizer has some specific advantages over the conventional spray techniques that use carrier gas for spraying, such as: fine atomization, no need for gas, improved wettability and precursor loss to the surroundings is almost nil [7].

\section{Experimental}

$\mathrm{CdO}$ thin films were prepared on glass substrates maintained at $400{ }^{\circ} \mathrm{C}$ by spray pyrolysis technique using perfume atomizer by spraying $50 \mathrm{~mL}$ of aqueous solution containing $0.05 \mathrm{M}$ of cadmium acetate, $\mathrm{Cd}\left(\mathrm{CH}_{3} \mathrm{COO}\right)_{2}$. To study the aging effect of the precursor solution, $\mathrm{CdO}$ thin films were prepared i) using fresh solution and ii) using solutions having different aging periods (1, 2, 3 and 4 days). The $\mathrm{CdO}$ thin films prepared from the precursor solutions having aging periods of $1,2,3$ and 4 days will hereafter be called as first day film, second day film, third day film and fourth day film, respectively. The thicknesses of the films measured using a stylus type profilometer (Surftest SJ 301) were found to be equal to 678,689, 697, 706 and $714 \mathrm{~nm}$ for the films prepared from fresh solution, first, second, third and fourth day films respectively. The crystal structure morphology, optical and electrical studies were performed using X-ray diffractometer (PANalytical - PW 340/60 X' pert $\mathrm{PRO})$ with $\mathrm{CuK} \alpha$ radiation $(\lambda=1.5406 \AA) \mathrm{X}$-ray source, scanning electron microscope (HITACHI S - 3000H), Perkin Elmer UV-Vis-NIR double beam spectrometer (LAMBDA 35) in the wavelength range of $300 \mathrm{~nm}$ to $1100 \mathrm{~nm}$ and four point probe setup, respectively.

\section{Results and discussion}

\subsection{Crystal structure}

Fig. 1 shows the XRD patterns of $\mathrm{CdO}$ thin films prepared from (a) fresh, (b) 1-day aged, (c) 2-days aged, (d) 3-days aged and (e) 4-days aged precursor solutions.

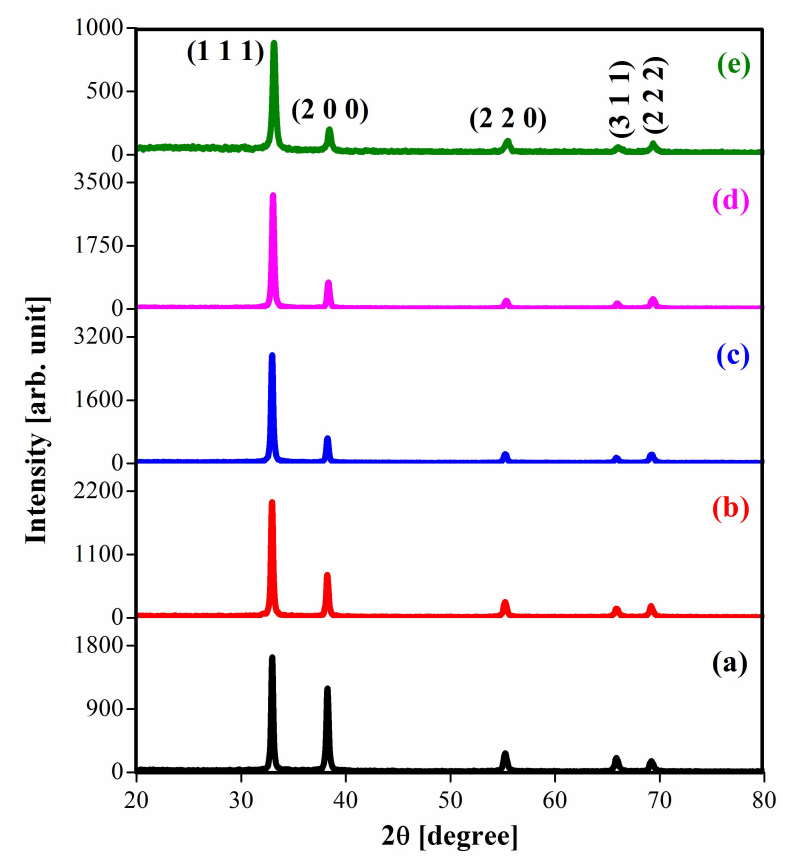

Fig. 1. XRD patterns of $\mathrm{CdO}$ thin films prepared from (a) fresh, (b) 1-day aged, (c) 2-days aged, (d) 3-days aged and (e) 4-days aged precursor solutions.

The presence of diffraction peaks at $2 \theta$ values approximately equal to $32.974^{\circ}, 38.255^{\circ}, 55.214^{\circ}$, $65.801^{\circ}$ and $69.088^{\circ}$ indexed to $\left(\begin{array}{lll}1 & 1 & 1\end{array}\right),\left(\begin{array}{lll}2 & 0 & 0\end{array}\right)$, (2 20 ), ( $\left.\begin{array}{lll}3 & 1 & 1\end{array}\right)$ and $\left(\begin{array}{lll}2 & 2 & 2\end{array}\right)$ planes of cubic $\mathrm{CdO}$ (JCPDS Card No. 73-2245) confirm the polycrystalline nature of the prepared films. It is observed that all the films exhibit a (lllll) preferential orientation irrespective of aging period of the starting solution. The preferential orientation along the $\left(\begin{array}{lll}1 & 1 & 1\end{array}\right)$ plane observed here, exactly matches with the results reported by Manjula et al. [11] and Usharani et al. [14] for undoped and doped $\mathrm{CdO}$ thin films prepared using perfume atomizer.

Fig. 2 shows the variation of the preferential orientation factor $\mathrm{f}(\mathrm{h} \mathrm{k} \mathrm{l})$ of the $\left(\begin{array}{lll}1 & 1 & 1\end{array}\right)$ plane 
calculated by the way adopted by Suganya et al. [15] as a function of aging period of the starting solution.

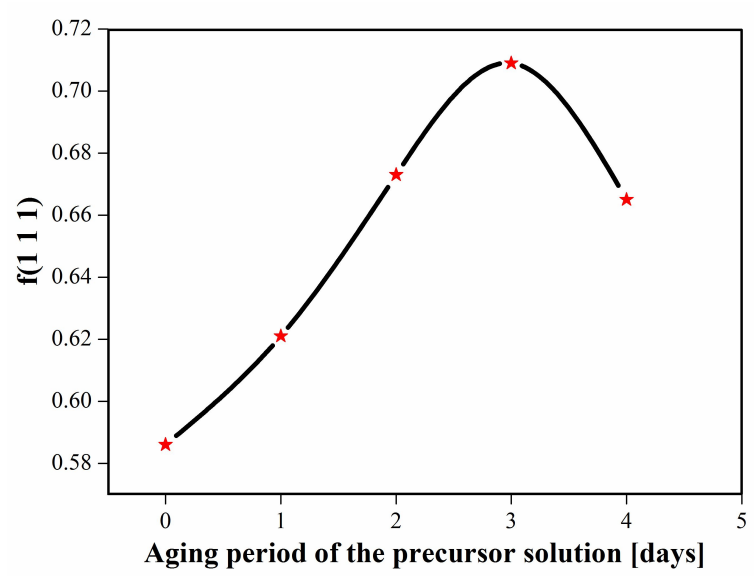

Fig. 2. Variation of $\mathrm{f}\left(\begin{array}{lll}1 & 1 & 1\end{array}\right)$ as a function of aging period of the precursor solution.

It is observed that $\mathrm{f}\left(\begin{array}{lll}1 & 1 & 1\end{array}\right)$ increases with an increase in aging period of the starting solution, attaining a maximum value for the $\mathrm{CdO}$ film prepared from 3-days aged solution and for further increase in aging period it slightly decreases. A close examination of the XRD patterns clearly shows that the $2 \theta$ value of the $\left(\begin{array}{lll}1 & 1 & 1\end{array}\right)$ plane shifts towards a lower Bragg angle (Table 1) for the aged films inferring an expansion in their lattice volume. The lattice parameter values calculated for the $\left(\begin{array}{lll}1 & 1 & 1\end{array}\right)$ plane are compiled in Table 1.

As expected, the lattice parameter values increase with an increase in aging period of the precursor solution, which might be due to a change in the crystal strain with aging. The deviation of the lattice parameter values from the bulk value observed here clearly suggests that the grains in the films are under stress. This deviation can be attributed to the change in the nature, deposition conditions and concentration of the native imperfections [16].

The microstructural parameters such as crystallite size (D), strain $(\epsilon)$ and dislocation density $(\delta)$ were calculated using the formulae [17]:

$$
D=\frac{0.9 \lambda}{\beta \cos \theta}
$$

$$
\varepsilon=\frac{\beta \cot \theta}{4}
$$

$$
\delta=\frac{1}{D^{2}}
$$

where $\lambda$ is the wavelength of the $\mathrm{X}$-ray used (1.5406 $\AA$ ), $\beta$ is the full width at half maximum of the strongest diffraction peak $\left(\left(\begin{array}{lll}1 & 1 & 1\end{array}\right)\right.$ in this case) measured in radians and $\theta$ is the Bragg angle. The variation of the microstructural parameters as a function of aging periods of the precursor solution is shown in Fig. 3.

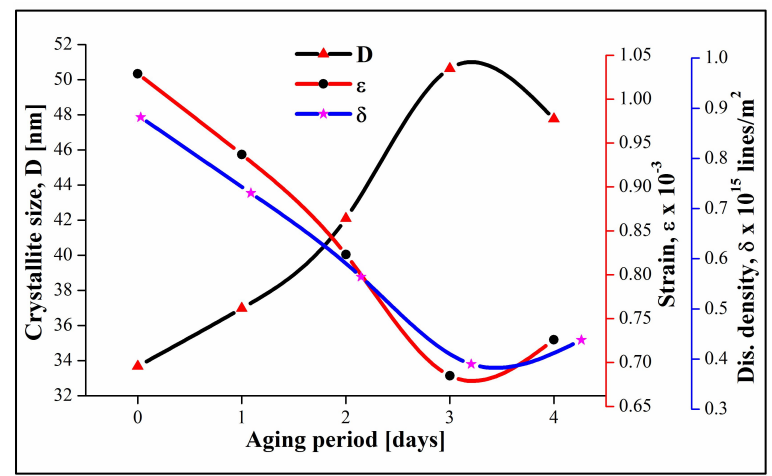

Fig. 3. Variation of microstructural parameters of $\mathrm{CdO}$ thin films as a function of aging period of the precursor solution.

It is observed that the crystallite size increases with an increase in aging period of the precursor solution, attaining a maximum value for the third day film confirming its improved crystallinity which is well supported by the minimum values of strain and dislocation density obtained for this film.

\subsection{Surface morphology and elemental analysis}

Fig. 4 shows the SEM images of $\mathrm{CdO}$ thin films prepared from precursor solutions having different aging periods.

The surfaces of all the films appear to be uniform and tightly packed. Caterpillar shaped grains along with cauliflower shaped nanostructures are visible for the $\mathrm{CdO}$ film prepared from the fresh solution (Fig. 4a). The surface gets modified with unequal sized tiny cauliflower shaped grains for 
Table 1. Structural parameters, elemental composition, optical band gap and electrical resistivity values of CdO films prepared from precursor solutions having different aging periods.

\begin{tabular}{|c|c|c|c|c|c|c|c|}
\hline \multirow{3}{*}{$\begin{array}{c}\text { Aging period } \\
\text { of the precursor solution } \\
\text { [days] }\end{array}$} & \multirow{3}{*}{$2 \theta\left(\begin{array}{lll}1 & 1 & 1\end{array}\right)$} & \multirow{3}{*}{$\begin{array}{c}\text { Lattice } \\
\text { parameter* } \\
{[\AA]} \\
\end{array}$} & \multirow{2}{*}{\multicolumn{3}{|c|}{$\begin{array}{c}\text { Element } \\
\text { composition [at.\%] }\end{array}$}} & \multirow{3}{*}{$\begin{array}{c}\text { Optical band } \\
\text { gap, } \mathrm{E}_{\mathrm{g}} \\
{[\mathrm{eV}]}\end{array}$} & \multirow{3}{*}{$\begin{array}{l}\text { Electrical resistivity, } \\
\qquad \times 10^{-2} \Omega \cdot \mathrm{cm}\end{array}$} \\
\hline & & & & & & & \\
\hline & & & $\mathrm{Cd}$ & $\mathrm{O}$ & $\mathrm{O} / \mathrm{Cd}$ & & \\
\hline 0 & $32.974^{\circ}$ & 24.7051 & 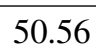 & 49.44 & 0.98 & 2.48 & 4.27 \\
\hline 1 & $32.953^{\circ}$ & 4.7081 & 49.87 & 47.79 & 0.96 & 2.42 & 3.09 \\
\hline 2 & $32.965^{\circ}$ & 4.7065 & 48.91 & 46.02 & 0.94 & 2.4 & 1.94 \\
\hline 3 & $32.950^{\circ}$ & 4.7086 & 48.02 & 44.81 & 0.93 & 2.35 & 0.78 \\
\hline 4 & $32.956^{\circ}$ & 4.7075 & 48.99 & 45.27 & 0.92 & 2.32 & 0.92 \\
\hline
\end{tabular}

${ }^{*}$ Standard $\mathrm{a}=4.699$ A (JCPDS Card No. 73-2245)
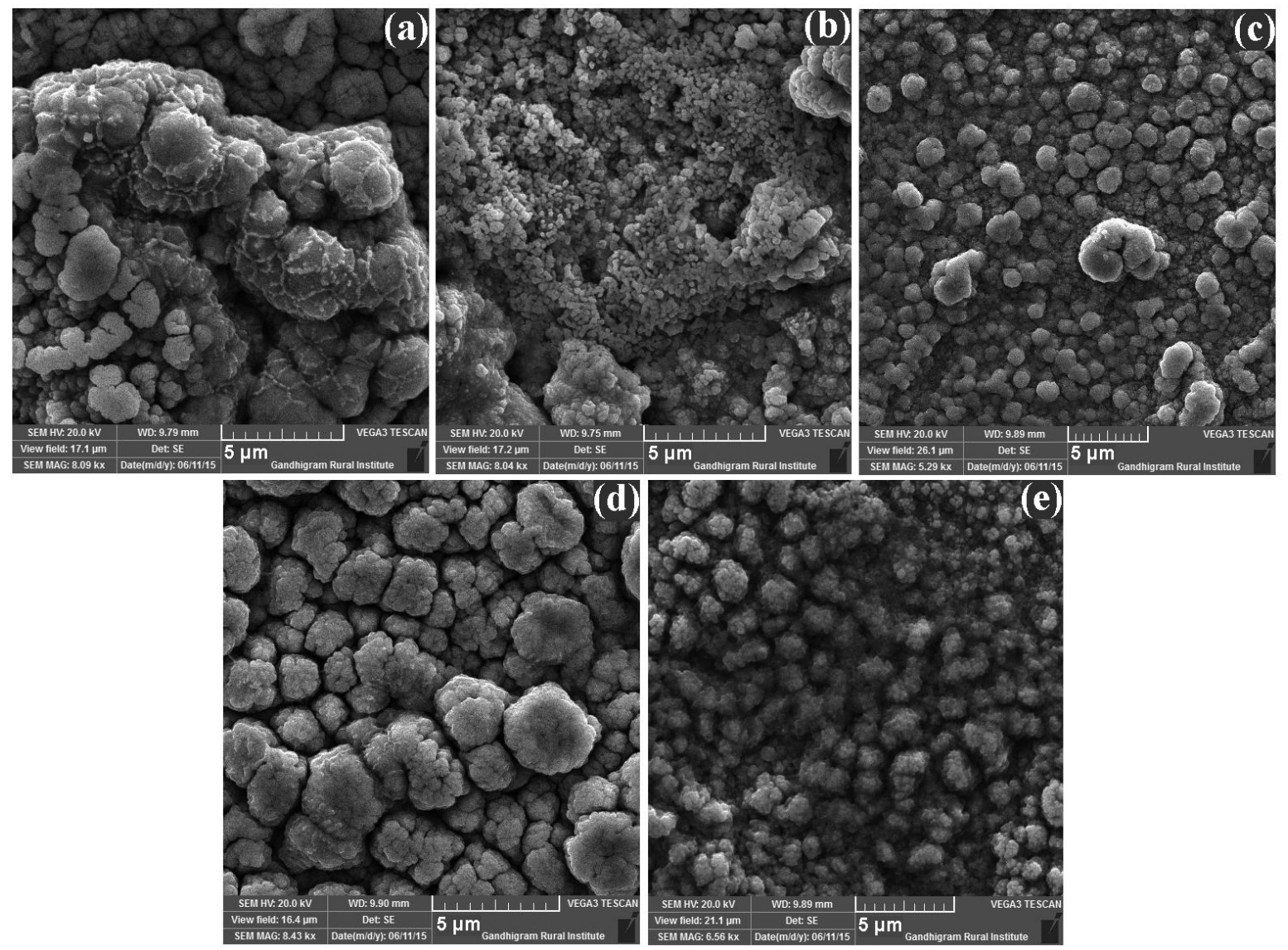

Fig. 4. SEM images of CdO thin films prepared from (a) fresh, (b) 1-day, (c) 2-days, (d) 3-days and (e) 4-days aged precursor solutions.

the film prepared from 1-day aged solution For the third day film, the surface gets modified (Fig. 4b). As the aging period of the precursor solution increases, the surface gets composed with equal sized cauliflower shaped grains for the $\mathrm{CdO}$ with perfectly shaped cauliflower structures. The surface appears to be smoother without any holes film coated with 2-days aged solution (Fig. 4c). or cracks (Fig. 4d). The film surface appears to be slightly deteriorated with unequal sized cauliflower 
shaped grains for the $\mathrm{CdO}$ film coated for the fourth day film (Fig. 4e). From the obtained results it is observed that among the aged films, the $\mathrm{CdO}$ film coated with 3-days aged precursor solution exhibited the best surface morphology which very well acknowledges the results obtained in XRD analysis (Section 3.1).

The elemental composition of the films was analyzed using energy dispersive X-ray analysis and the composition of the elements $\mathrm{Cd}$ and $\mathrm{O}$ are compiled in Table 1. It is observed that the content of both $\mathrm{Cd}$ and $\mathrm{O}$ decreases with an increase in aging period of the starting solution. It can be seen that the aged films become non-stoichiometric in nature $(\mathrm{O} / \mathrm{Cd}<1)$ i.e. the aged films are oxygen deficient. The increased oxygen vacancies observed with increased aging period of the precursor solution might have played a vital role in influencing the electrical resistivity of the aged film as can be seen in the electrical studies (Section 3.3).

\subsection{Electrical studies}

The electrical resistivity values of $\mathrm{CdO}$ thin films prepared from the precursor solution having different aging periods are given in Table 1. All the films have resistivity of the order of $10^{-2} \Omega \cdot \mathrm{cm}$. It is observed that the $\mathrm{CdO}$ film prepared from fresh solution has a resistivity of $4.27 \times 10^{-2} \Omega \cdot \mathrm{cm}$ which decreased to a minimum value of $0.78 \times 10^{-2} \Omega \cdot \mathrm{cm}$ for the third day film and for further increase in aging period it slightly increased. The reduction in the resistivity observed with aging period of the precursor solution may be attributed to the rise of free carriers due to increased oxygen vacancies which act as donors. The minimum value of resistivity obtained for the third day film might be due to the decreased strain and dislocation density values obtained for this film (Fig. 3). The slight increment in the resistivity value of the fourth day film might be due to the decrease in free carrier concentration which might have occurred due to the instability of the chemical species formed due to the aging of the solution.

\subsection{Optical studies}

Fig. 5 shows the absorption and transmittance spectra of CdO films prepared from precursor solutions having different aging periods.

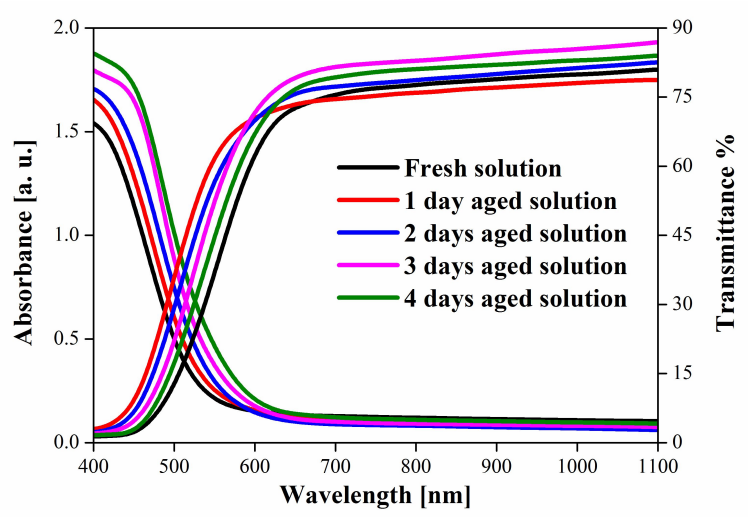

Fig. 5. Absorbance and transmittance spectra of $\mathrm{CdO}$ thin films prepared from precursor solutions having different aging periods.

It is observed that the transparency of the $\mathrm{CdO}$ films increases with an increase in the aging period of the starting solution, which might have resulted from enhanced diffusion of chemical species in the precursor solution with aging. Moreover, all the films have the same absorption edge and the absorbance increases with an increase in the aging period of the solution. It can also be seen that the absorption edge shifts towards higher wavelength side with the aging period of the starting solution, indirectly suggesting a decrement in their band gap values.

The optical band gap energy $\left(\mathrm{E}_{\mathrm{g}}\right)$ was calculated from the absorption spectra using the dependence of the absorption coefficient $(\alpha)$ on the photon energy (hv) by the relation [18]:

$$
\alpha h v=A\left(h v-E_{g}\right)^{1 / 2}
$$

where $\mathrm{A}$ is a constant. Fig. 6 shows the plots of $(\alpha h v)^{2}$ vs. (hv) for the films. From the extrapolation of the linear portion of the plots onto the energy axis at $\alpha=0$ the band gap values of the films were calculated and the obtained values are compiled in Table 1.

The band gap value of the $\mathrm{CdO}$ film prepared from fresh precursor solution $(2.48 \mathrm{eV})$ is found to 


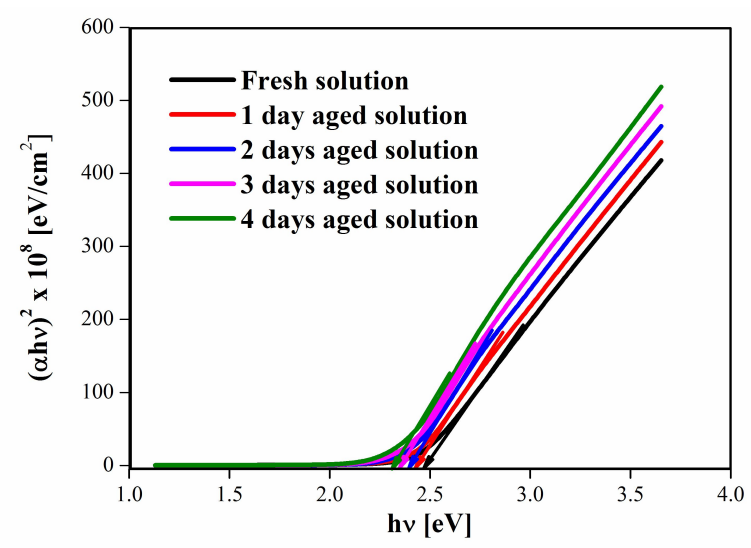

Fig. 6. Plots of $(\alpha h v) 2$ versus $(h v)$ of $\mathrm{CdO}$ thin films prepared from precursor solution having different aging periods.

be slightly lower than that of bulk $\mathrm{CdO}(2.42 \mathrm{eV})$ and the blue shift could be attributed to quantum confinement effect. This is in accordance with the results reported by Usharani et al. [19] for Cl-doped $\mathrm{ZMCO}$ thin films. It is observed that the band gap energy decreased from $2.48 \mathrm{eV}$ to $2.32 \mathrm{eV}$ with an increase in the aging period of the starting solution. This red shift in the optical band gap with aging may be due to the influence of various factors such as grain size, structural parameters, carrier concentration, deviation from stoichiometry of the films and lattice strain [20].

\section{Conclusions}

Precursor solutions with different aging periods were used to prepare $\mathrm{CdO}$ thin films by spray technique using perfume atomizer. The films were characterized structurally, morphologically, optically and electrically to study the influence of aging period of the precursor solution on the physical properties of $\mathrm{CdO}$ thin films. Structural studies confirmed the polycrystalline nature of the films. All the films exhibited cubic crystal structure with preferential orientation along the $\left(\begin{array}{lll}1 & 1 & 1\end{array}\right)$ plane. Crystallite size estimated using the Scherrer formula increased from $33.68 \mathrm{~nm}$ to $50.64 \mathrm{~nm}$ with an increase in the aging period of the solution. An increased crystallite size of $50.64 \mathrm{~nm}$, decreased strain and dislocation density values of
$0.685 \times 10^{-3}$ and $0.390 \times 10^{15}$ lines per $\mathrm{m}^{2}$ respectively were observed for the $\mathrm{CdO}$ film prepared from 3 days aged solution. Optical transparency was found to be increased with an increase in aging period of the precursor solution. Electrical resistivity decreased with an increase in the aging period of the starting solution and the third day film exhibited a minimum resistivity value of $0.78 \times 10^{-2} \Omega \cdot \mathrm{cm}$. The obtained results infer that among the aged films, CdO film prepared from 3 days aged precursor solution exhibited the best physical properties.

\section{References}

[1] Gulino A., Castelli F., Dapporto P., Rossi P., Fragala I., Chem. Mater., 14 (2002) 704.

[2] Moholkar A.V., Agawane G.L., Sim K.U., Kwon Y., Choi D.S., Rajpure K.Y., Kim J.H., J. Alloy. Compd., 506 (2010) 794.

[3] Shanmugavel G., Balu A.R., Ngarethinam V.S., Int. J. Chem. Mater. Res., 2 (2014) 88.

[4] Farag A.A.M., CaVAn M., Yakuphanoglu F., Mater. Chem. Phys., 132 (2012) 550.

[5] Ueda N., Maeda H., Hosono H., Kawazoe H., J. Appl. Phy., 84 (1998) 6174.

[6] Yan M., Lane M., Kannewurf C.R., Chang R.P.H., Appl. Phys. Lett., 78 (2001) 2342.

[7] Usharani K., Balu A.R., Shanmugavel G., SugANYA M., NAGAREthinam V.S., Int. J. Sci. Res. Rev., 2 (2013) 53.

[8] Maity R., Chattopadhyay K.K., Sol. Energ. Mat. Sol. C., 90 (2006) 597.

[9] Balu A.R., Nagarethinam V.S., Suganya M., Arunkumar N., Selvan G., J. Electron. Device., 12 (2012) 739.

[10] Usharani K., Raja N., Manjula N., NAgarethiNAM V.S., BALU A.R., Int. J. Thin Film Sci. Technol., 2 (2015) 89.

[11] Manjula N., Balu A.R., Int. J. Chem. Phys. Sci., 3 (2014) 54.

[12] Li Y., Xu L., Li X., Shen X., Wang A., Appl. Surf. Sci., 256 (2014) 4541.

[13] Selvan G., Abubacker M.P., Usharani K., Balu A.R., Surf. Eng., 32 (2015) 212.

[14] Usharani K., Balu A.R., Acta Metall. Sinica, 28 (2014) 68.

[15] Suganya M., Balu A.R., Usharani K., Mater. Sci.-Poland, 32 (2014) 448.

[16] Syed Basher Ahamed M.G., NAGarethinam V.S., Balu A.R., Thayumanavan A., Murali K.R., SAnJeEviraja C., Jayachandran M., Cryst. Res. Technol., 45 (2010) 421.

[17] Ravishankar S., Balu A.R., Anbarasi M., NAGARETHINAM V.S., Optik, 126 (2015) 2550.

[18] Rajashree C., Balu A.R., Nagarethinam V.S., Surf. Eng., 31 (2015) 316. 
[19] Usharani K., Balu A.R., Nagarethinam V.S., Surf. Eng., 32 (2016) 829.

[20] Lejimi N., Savadoga O., Solar. Energ. Mat. Sol. C., 70 (2001) 71 .

Received 2016-04-12

Accepted 2018-12-17 